\title{
Влияние термических условий получения и обработки на оптические свойства пленок $\ln _{2} \mathrm{O}_{3}$
}

\author{
(C) А.А. Тихий ${ }^{1}$, Ю.М. Николаенко ${ }^{1}$, Ю.И. Жихарева ${ }^{2}$, А.С. Корнеевец ${ }^{1}$, И.В. Жихарев ${ }^{1}$ \\ ${ }^{1}$ Донецкий фризико-технический институт им. А.А. Галкина, \\ 83114 Донецк, Украина \\ 2 Государственный университет телекоммуникаций, \\ 03680 Киев, Украина \\ E-mail: ea0000ffff@mail.ru
}

(Получена 29 марта 2017г. Принята к печати 17 апреля 2017г.)

Пленки $\mathrm{In}_{2} \mathrm{O}_{3}$ на положках $\mathrm{Al}_{2} \mathrm{O}_{3}(012)$ получены методом $d c$-магнетронного распыления при различных температурах $\left(20-600^{\circ} \mathrm{C}\right)$. Исследование влияния отжига и температуры подложки на свойства пленок производилось эллипсометрическим методом и методом оптического пропускания. Построены профили показателя преломления; найдены значения ширины запрешенной зоны для прямых и „непрямых“ переходов. Установлено, что отжиг приводит к уплотнению материала пленок и унификации значений показателя преломления. Также отжиг понижает и унифицирует энергии переходов зона-зона, что можно объяснить уменьшением влияния барьеров в отожженных пленках. Однако ширина запрещенной зоны для прямых переходов изменяется сильнее, чем для „непрямых“. Это может быть связано с механизмом непрямых переходов - участие фононов облегчает межзонные переходы, даже если им препятствует наличие дополнительных барьеров, обусловленных границами зерен. Последнее может быть косвенным свидетельством реальности непрямых переходов в оксиде индия.

DOI: 10.21883/FTP.2018.03.45618.8596

\section{1. Введение}

Полупроводники $\mathrm{In}_{2} \mathrm{O}_{3}$ являются достаточно известными и неплохо изученными материалами. Тем не менее интерес исследователей к пленкам этих материалов не ослабевает, что обусловлено рядом их уникальных свойств. Так, будучи оптически прозрачными, пленки $\mathrm{In}_{2} \mathrm{O}_{3}$ обладают высокой электропроводностью, которая весьма чувствительна к составу окружающей атмосферы. При этом изменения электропроводности в зависимости от состава окружающей газовой среды малоинерционны и носят обратимый характер. Пленки $\mathrm{In}_{2} \mathrm{O}_{3}$ уже нашли широкое применение в качестве прозрачных контактов и газовых сенсоров. Допирование $\mathrm{In}_{2} \mathrm{O}_{3}$ различными примесями позволяет в широких пределах менять свойства пленок - их электропроводность, чувствительность к различным газам и др.

\section{2. Объекты и методы исследований}

Нами исследовались оптические свойства пленок $\mathrm{In}_{2} \mathrm{O}_{3}$, полученных методом $d c$-магнетронного распыления [1] на подложки $\operatorname{In}_{2} \mathrm{O}_{3}(012)$. Напыление в атмосфере аргон-кислород выполнялось при температурах подложек 600,300 и $20^{\circ} \mathrm{C}$ в течение 1 ч; рабочий ток составлял 50 мА, напряжение 300 В. Оптические свойства пленок изучались методами спектрофотометрии в диапазоне длин волн от 190 до $1100 \mathrm{Hм}$ (энергий фотонов $1-6$ эВ) и отражательной многоугловой эллипсометрии на длине волны гелий-неонового лазера (632.8 нм). Эллипсометрические измерения выполнялись с целью исследования структуры пленки; спектрофотометрические измерения - с целью установления характера переходов зона-зона и ширины запрещенной зоны из анализа края фундаментального поглощения в спектрах оптического пропускания.

\section{1. Эллипсометрические исследования}

Интерпретация результатов измерений эллипсометрических углов $\Psi$ и $\Delta$, зависящих от длины волны зондирующего излучения $\lambda$, угла падения $\varphi$, толщины $d$ и показателя преломления $n$ прозрачной пленки, а также показателя преломления прозрачной подложки $n_{0}$, производилась минимизационным методом, согласно разработанной нами ранее методике комплексного исследования тонкопленочных покрытий, основанной на совместном использовании данных эллипсометрических измерений и величины оптического пропускания [2]. Целевая функция имела вид

$$
\begin{aligned}
G= & M \frac{\left(T^{(\mathrm{e})}-T^{(\mathrm{c})}\right)^{2}}{\left(T^{(\mathrm{e})}\right)^{2}} \\
& +\sum_{i=1}^{M}\left(\frac{\left(\Psi_{i}^{(\mathrm{e})}-\Psi_{i}^{(\mathrm{c})}\right)^{2}}{\left(\Psi_{i}^{(\mathrm{e})}\right)^{2}}+\frac{\left(\Delta_{i}^{(\mathrm{e})}-\Delta_{i}^{(\mathrm{c})}\right)^{2}}{\left(\Delta_{i}^{(\mathrm{e})}\right)^{2}}\right)
\end{aligned}
$$

Индексы (е) и (с) соответствуют экспериментальным и расчетным значениям $\Psi$ и $\Delta, T-$ коэффициент оптического пропускания на длине волны 633 нм, $M-$ число измерений при различных углах падения зондирующего излучения. Переходные слои на поверхности пленок моделировались как совокупности физически бесконечно тонких слоев фиксированной толщины с 


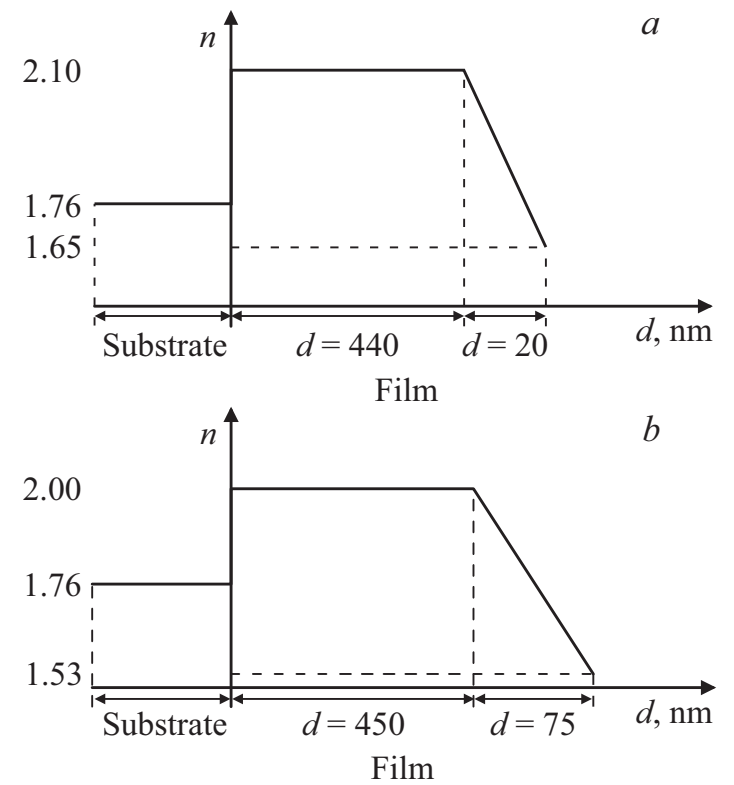

Рис. 1. Профили показателей преломления пленок, нанесенных на подложки с температурой $600^{\circ} \mathrm{C}(a)$ и $300^{\circ} \mathrm{C}(b)$.
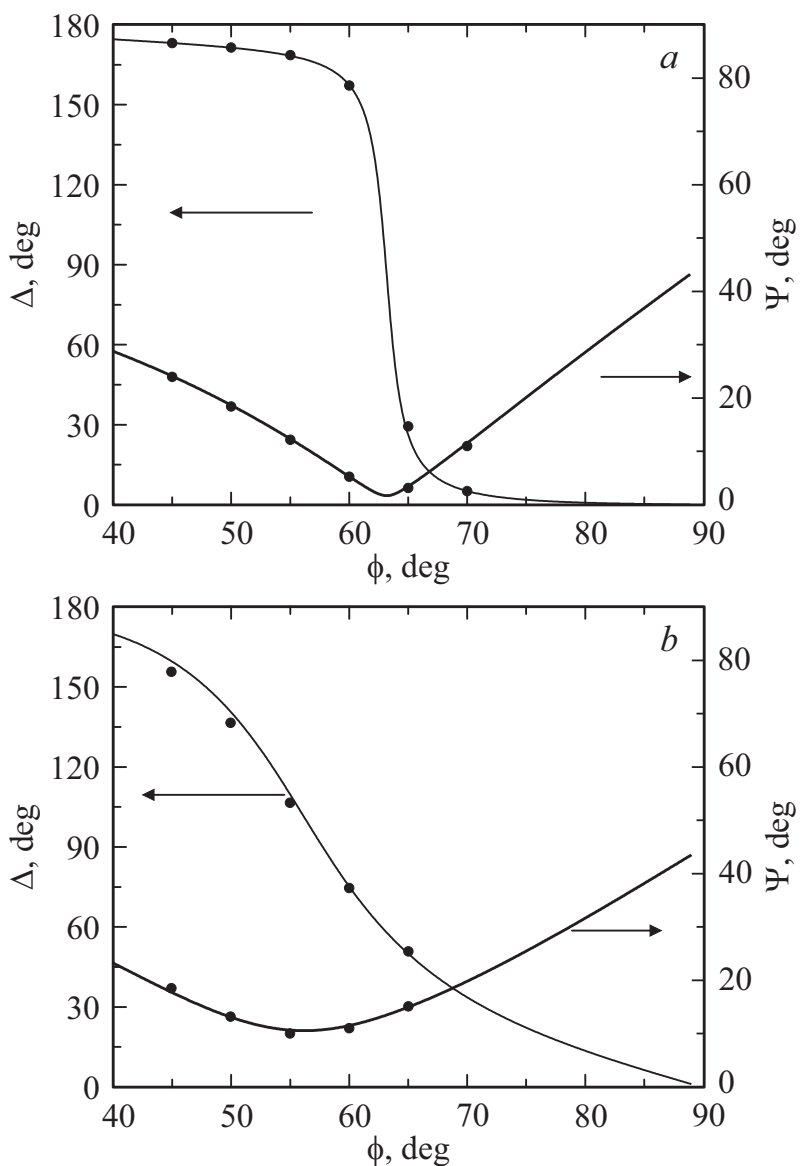

Рис. 2. Вычисленные (сплошные линии) и экспериментальные (символы) зависимости эллипсометрических углов $\Delta$ и $\Psi$ от угла падения для пленок, нанесенных на подложки с температурой $600^{\circ} \mathrm{C}(a)$ и $300^{\circ} \mathrm{C}(b)$.
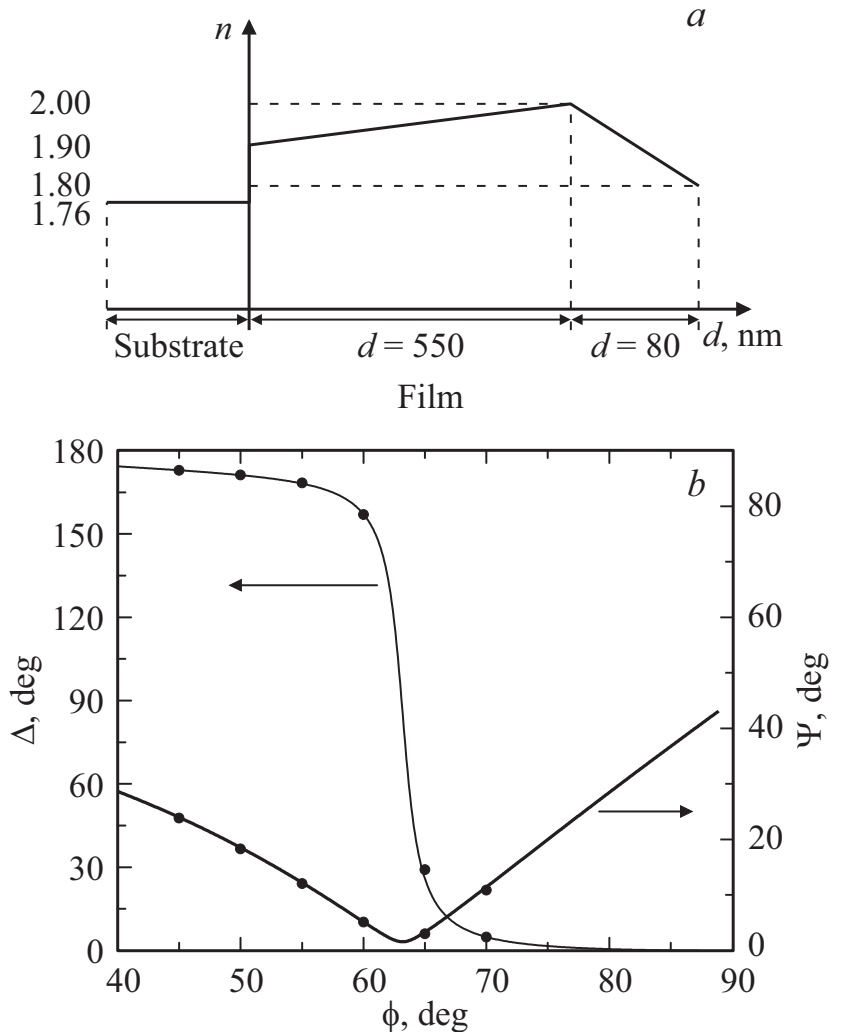

Рис. 3. Результаты эллипсометрических измерений пленок, нанесенных на подложки с температурой $20^{\circ} \mathrm{C}: a-$ профиль показателя преломления; $b-$ вычисленные (сплошные линии) и экспериментальные (символы) зависимости эллипсометрических углов $\Delta$ и $\Psi$ от угла падения $\varphi$.

показателем преломления, изменяющимся по заданным линейным законам [3].

Двулучепреломление сапфира не учитывалось, так как благодаря специальной ориентации образца оно в процессе измерения не оказывало влияния на результат. Так как исследованные пленки являются прозрачными для света с длиной волны $633 \mathrm{Hм}$, было достаточно минимизировать целевую функцию в координатах $(n, d)$.

В результате применения указанной методики к пленкам $\mathrm{In}_{2} \mathrm{O}_{3}$ на подложках $\mathrm{Al}_{2} \mathrm{O}_{3}$ было установлено, что пленки, нанесенные на подложки с температурой $300^{\circ} \mathrm{C}$ и более являются однородными по толщине, но имеют поверхностный нарушенный слой. При этом толщины пленки и нарушенного слоя тем меньше, чем выше была температура подложки, на которую они наносились. Показатель преломления, наоборот, возрастает с увеличением температуры подложки. Полученные результаты для „горячих“ (300 и 600 $\mathrm{C}$ ) подложек иллюстрируются профилями коэффициента преломления с указанием соответствующих толщин (рис. 1). На рис. 2 представлены экспериментально полученные и расчетные зависимости эллипсометрических углов $\Psi$ и $\Delta$ от угла падения эллиптически поляризованного света, показывающие хорошее согласие эксперимента 
Прямые и „непрямые“ переходы в пленках $\operatorname{In}_{2} \mathrm{O}_{3}$

\begin{tabular}{c|c|c|c|c|c|c}
\hline \multirow{2}{*}{$\begin{array}{c}\text { Температура } \\
\text { подложки, }{ }^{\circ} \mathrm{C}\end{array}$} & \multicolumn{3}{|c|}{ До отжига } & \multicolumn{3}{c}{ После отжига } \\
\cline { 2 - 7 } & $E_{g}^{\Gamma}$, эВ & $E_{g}^{\text {indir }}$, эВ & $\Delta E$, эB & $E_{g}^{\Gamma}$, эB & $E_{g}^{\text {indir }}$, эB & $\Delta E$, эВ \\
\hline 20 & 4.07 & 2.94 & 1.13 & 3.71 & 2.69 & 1.02 \\
600 & 3.72 & 2.72 & 1.00 & 3.71 & 2.67 & 1.04
\end{tabular}

с результатами расчетов. Наблюдаемые зависимости в изменениях оптических параметров пленок $\mathrm{In}_{2} \mathrm{O}_{3}$ в зависимости от температуры подложки достаточно закономерны - чем выше температура подложки в процессе напыления, тем более плотным и менее дефектным является материал пленки.

На рис. 3 представлены результаты обработки данных эллипсометрических измерений пленки $\mathrm{In}_{2} \mathrm{O}_{3}$, нанесенной на „холодную“ $\left(20^{\circ} \mathrm{C}\right)$ подложку $\mathrm{Al}_{2} \mathrm{O}_{3}$. Из рисунка видно, что показатель преломления слоя собственно исследуемого материала сначала возрастает от 1.9 у границы подложка-пленка, а затем линейно уменьшается в нарушенном слое с 2 до 1.8. При этом материал пленки „рыхлый“ - ее общая толщина, как толщина нарушенного слоя, больше, чем у пленок на „горячих“ подложках. Полученные результаты в целом согласуются с вышеизложенными соображениями. Что касается роста показателя преломления в базовом материале пленки, то он, по-видимому, связан с повышением температуры поверхности растущей пленки в процессе ее напыления.

В результате отжигов свойства исследованных пленок унифицируются, улучшается однородность распределения показателя преломления по толщине, уменьшается толщина пленки и нарушенного слоя - происходит уплотнение материала. Толщины всех отожженных пленок приближаются к 400 нм, показатели преломления к 2, а толщина нарушенного слоя - 21 нм.

\section{2. Исследование края фундаментального поглощения}

Особый интерес представляет изучение края фундаментального поглощения в зависимости от температуры подложки в процессе нанесения пленок $\operatorname{In}_{2} \mathrm{O}_{3}$. Это связано с дискуссией относительно характера межзонных переходов в этих материалах $[4,5]$.

Наблюдаемые спектры поглощения, представленные в работах [6,7], свидетельствуют о наличии переходов с энергией $E_{g}^{\text {indir }}=2.62-2.69$ эB, интерпретируемых как непрямые, переходы зона-зона, и прямых с энергией $E_{g}^{\Gamma}=3.56-3.75$ эВ. Однако авторы работ $[4,5]$ на основании расчетов электронной структуры бездефектного оксида индия пришли к выводу о том, что различие в энергиях прямых и непрямых переходов не превышает 50 мэВ, а наблюдаемые „непрямые“ переходы связаны с несовершенствами структуры материала. В качестве экспериментального подтверждения авторы ссылаются на обнаруженные в оксидах индия пограничные эффекты и связанные с ними обедненные слои (с характерной энергией активации 2.2. -3.5 эВ относительно потолка валентной зоны) $[5,8,9]$. В связи с этим представляются важными эксперименты, направленные на исследование края фундаментального поглощения пленок $\operatorname{In}_{2} \mathrm{O}_{3}$ в зависимости от степени их несовершенства.

Ширина запрещенной зоны для прямых $E_{g}^{\Gamma}$ и „непрямых“ $E_{g}^{\text {indir }}$ переходов зона-зона нами оценивалась
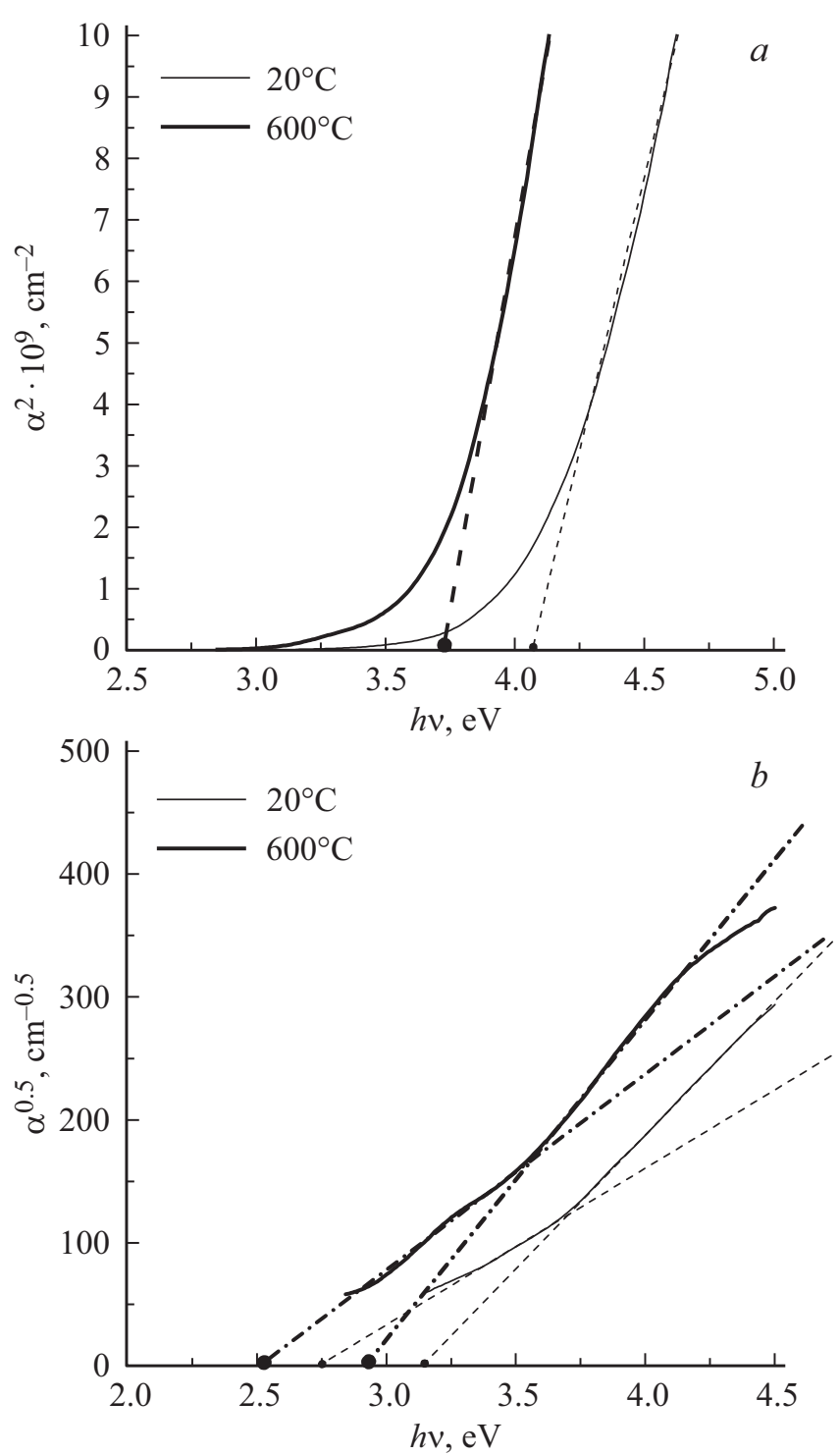

Рис. 4. Зависимости коэффициента поглощения $\alpha^{2}$ (a) и $\alpha^{1 / 2}(b)$ от энергии фотонов для пленок, нанесенных на подложки с температурой 20 и $600^{\circ} \mathrm{C}$, до отжига. 

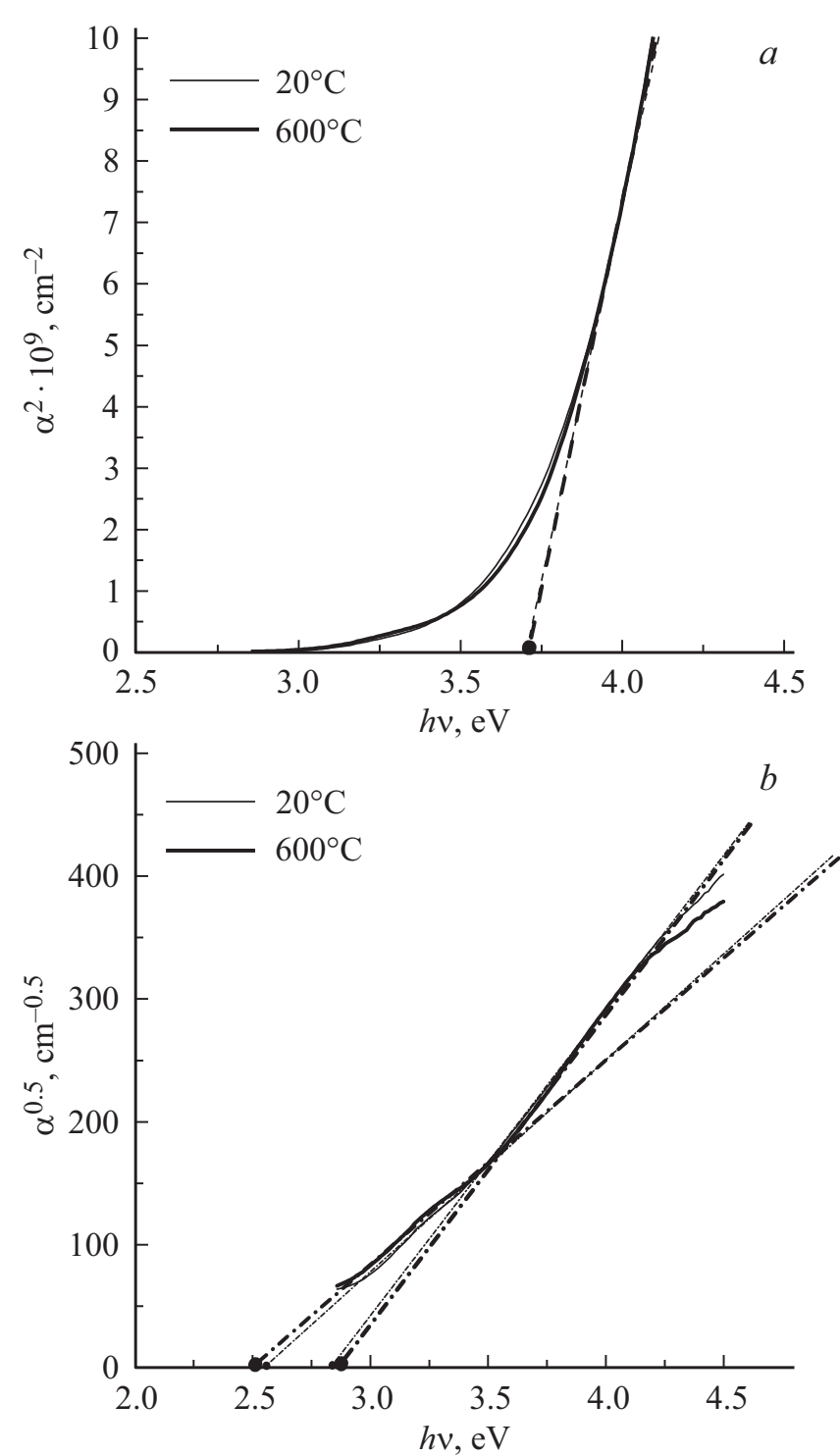

Pис. 5. Зависимости коэффициента поглощения $\alpha^{2}$ (a) и $\alpha^{1 / 2}(b)$ от энергии фотонов для пленок, нанесенных на подложки с температурой 20 и $600^{\circ}$ после отжига.

по краю фундаментального поглощения. На рис. 4,5 показаны соответствующие зависимости коэффициента поглощения $\alpha^{2}$ и $\alpha^{0.5}$ от энергии фотонов, вычисленные по результатам измерений оптического пропускания и эллипсометрических измерений. Полученные значения энергий переходов представлены в таблице.

Как видно из рис. 4,5 и данных таблицы, ширина запрещенной зоны тем меньше, чем выше температура подложки в процессе напыления пленок. Эти результаты вполне закономерны - степень дефектности пленки, нанесенной на „горячую“ подложку, меньше. Отжиг приводит к унификации свойств пленок и по ширине запрещенной зоны. Разность энергий прямых и „непрямых“ переходов $\Delta E=E_{g}^{\Gamma}-E_{g}^{\text {indir }}$ для всех пленок составляет около 1 эВ, что согласуется с данными работ $[10,11]$, за исключением неотожженных пленок на холодной подложке. Отжиг последних приводит к снижению величины $\Delta E$, при этом ширина запрещенной зоны для прямых переходов изменяется сильнее, чем для „непрямых“, т. е. отжиг влияет преимущественно на энергию прямых переходов. Это может быть связано с механизмом непрямых переходов - участие фононов облегчает межзонные переходы, даже если им препятствует наличие дополнительных барьеров, обусловленных границами зерен.

\section{3. Заключение}

По результатам эллипсометрических измерений установлено, что в результате отжига происходит унификация свойств всех исследованных пленок, а также уплотнение их материала и улучшение его однородности. Следует отметить, что отжиг оказал наибольшее формирующее действие на пленку, нанесенную на „холодную“ подложку. Влияние отжига на две другие пленки незначительно.

Очевидными результатами отжига являются устранение структурных дефектов, рост размеров зерен и, как следствие, уплотнение материала пленки. Таким образом, понижение энергии межзонных переходов можно объяснить ослаблением влияния барьеров в отожженных пленках. Меньшее влияние отжига на энергии непрямых переходов вызвано тем, что фононы, участвующие в непрямых переходах, имеют различные значения энергий и волновых векторов. Последнее, возможно, является косвенным свидетельством существования непрямых переходов в $\mathrm{In}_{2} \mathrm{O}_{3}$ и говорит о необходимости дальнейших исследований, направленных на установление характера электронных переходов зона-зона в этом соединении.

\section{Список литературы}

[1] Ю.М. Николаенко, А.Б. Мухин, В.А. Чайка, В.В. Бурховецкий. ЖТФ, 80, 115 (2010).

[2] А.А. Тихий, В.А. Грицких, С.В. Кара-Мурза, Ю.М. Николаенко, И.В. Жихарев. Опт. и спектр., 112, 329 (2012).

[3] А.А. Тихий, В.А. Грицких, С.В. Кара-Мурза, Н.В. Корчикова, Ю.М. Николаенко, В.В. Фарапонов, И.В. Жихарев. Опт. и спектр., 119, 282 (2015).

[4] P. Erhart, A. Klean, R.G. Egdell, K. Albe. Phys. Rev. B, 75, 153205 (2007).

[5] A. Klein. Appl. Phys. Lett., 77, 2009 (2000).

[6] Y. Gassenbauer, R. Schafranek, A. Klein, S. Zafeiratos, M. Hävecker, A. Knop-Gericke, R. Schlögl. Phys. Rev. B, 73, 245312 (2006).

[7] D.R. Lide (eds). Handbook of Chemistry and Physics, 85th edn (CRC Press, Boca Raton, FL (2004)).

[8] Y. Gassenbauer, R. Schafranek, A. Klein, S. Zafeiratos, M. Hävecker, A. Knop-Gericke, R. Schlögl. Phys. Rev. B, 73, 245312 (2006).

[9] S.P. Harvey, T.O. Mason, Y. Gassenbauer, R. Schafranek, A. Klein. J. Phys. D: Appl. Phys., 39, 3959 (2006). 
[10] R.A. Pollak, S. Kowalczyk, L. Ley, D.A. Shirley. Phys. Rev. Lett., 29, 274 (1972).

[11] T. Kendelewicz, P.H. Mahowald, K.A. Bertness, C.E. McCants, I. Lindau, W.E. Spicer. Phys. Rev. B, 36, 6543 (1987).

Редактор А.Н. Смирнов

\section{The properties of $\ln _{2} \mathrm{O}_{3}$ films, deposited by dc-magnetron sputtering on $\mathrm{Al}_{2} \mathrm{O}_{3}$ substrates with different temperatures}

A.A. Tikhii ${ }^{1}$, Yu.M. Nikolaenko' ${ }^{1}$, Yu.I. Zhikhareva ${ }^{2}$, A.S. Kornievets ${ }^{1}$, I.V. Zhikharev ${ }^{1}$

${ }^{1}$ Donetsk Institute for Physics and Engineering named after A.A. Galkin,

83114 Donetsk, Ukraine

${ }^{2}$ State University of Telecommunications, 03680 Kyiv, Ukraine

Abstract The $\mathrm{In}_{2} \mathrm{O}_{3}$ films was deposited by dc-magnetron sputtering on substrates of $\mathrm{Al}_{2} \mathrm{O}_{3}(012)$ at different temperatures $\left(20-600^{\circ} \mathrm{C}\right)$. Ellipsometric and optical transmission measurements used to investigate the effect of substrate temperature and annealing on the properties of the films. The profiles of refractive index, direct and ,indirect" band gap determined. Annealing leads to compaction of the films' material and unifies the values of refractive index. Also the annealing reduces and unifies the energies of band-to-band transitions. This can be explained by a decrease of influence of barriers in the annealed films. But, the width of direct band gap is changed more than ,indirect" one. It seems that this is related to the mechanism of indirect transitions - phonon participation facilitates the interband transitions, even if they are hampered by the presence of extra barriers caused by grain boundary. The last result may indirectly evidence of the existence of indirect transitions in this material. 